\title{
A Unique Neuronal Organization in the Cat Pretectum Revealed by Antibodies to the Calcium-binding Protein Calbindin-D 28K
}

\author{
L. Burt Nabors and R. Ranney Mize \\ Department of Anatomy and Neurobiology, College of Medicine, University of Tennessee at Memphis, The Health \\ Science Center, Memphis, Tennessee 38163
}

\begin{abstract}
The pretectum is an important center for visual reflexes. However, the location, boundaries, and connections of individual nuclei of the pretectum are incompletely understood. In cat, the traditionally defined nuclear boundaries have been placed in doubt by recent evidence showing that the retinal input to the pretectum forms four continuous projection zones that do not match the cytoarchitectural boundaries of individual pretectal nuclei defined by previous studies. We now show that antibodies to the calcium-binding protein calbindin-D 28K (CaBP) label clusters of neurons within the pretectum that match the zones of retinal termination. Four obvious cell clusters within the pretectum were labeled by CaBP antisera. Computer three-dimensional reconstruction of these cell clusters revealed that they form four distinct but continuous zones that run the rostrocaudal length of the pretectum in a medial-to-lateral direction. By combining anterograde HRP labeling of retinal terminals with CaBP immunocytochemistry, these CaBP-labeled cell clusters were found virtually to overlap the retinal projection zones. The CaBP-labeled neurons included both multipolar and fusiform morphologies, and most were medium- to largesized cells. HRP retrograde transport studies showed that many CaBP-labeled neurons in the clusters projected to the LGN, while none projected to the inferior olive (IO). GABAimmunoreactive neurons were also found within the CaBP cell clusters, but these neurons were smaller than most CaBP. labeled neurons, and none were retrogradely labeled following HRP injections into the LGN or 10. Two-color antibody double-labeling experiments did not reveal any GABA neurons within the clusters that colocalized CaBP. In summary, calbindin is a precise marker of neuron clusters that overlap the retinal projection zones in the cat pretectum. Many of these CaBP neurons project to the LGN, and none contain GABA.
\end{abstract}

\footnotetext{
Received Jan. 8, 1991; revised Mar. 6, 1991; accepted Mar. 12, 1991.

This work was funded by U.S. Public Health Service Grant NIH EY-02973 from the National Eye Institute, by the Howard Hughes Medical Institute, and by the Neuroscience Center of Excellence of the State of Tennessee. L.B.N. was supported by a Howard Hughes Medical Student Research Training Fellowship. We thank Grace Butler for preparing the two-chromagen antibody double-label material and C. J. Jeon for assisting with some of the immunocytochemistry experiments. Robin Lawsun plutted some of the CaBP-labeled tissue sections with the NTS computer. We also thank Dr. Piers Emson of the Medical Research Council Group, Agricultural and Food Research Council, Institute of Animal Physiology and Genctics Research, Cambridge, England, for providing us with his calbindin antibody and Dr. Robert Wenthold of NIH, Bethesda, Maryland, for providing us with his GABA antibody.

Correspondence should be addresscd to Dr. R. Ranney Mize, Department of Anatomy and Neurobiology, College of Medicine, University of Tennessee, 875 Monroe Avenue, Memphis, TN 38163

Copyright (C) 1991 Society for Neuroscience 0270-6474/91/112460-17\$03.00/0
}

The pretectal nuclear complex in the cat traditionally has been described as composed of five to seven component nuclei (Rose, 1942; Kanaseki and Sprague, 1974; Berman and Jones, 1982). The nomenclature of Kanaseki and Sprague (1974) is commonly used for cat and includes the nucleus of the optic tract (NOT), olivary pretectal nucleus (OPN), posterior pretectal nucleus (PPN), anterior pretectal nucleus (APN), medial pretectal nucleus (MPN), and the subopticus nucleus (Kanaseki and Sprague, 1974). Afferents to this complex are largely from visually related structures, including principal projections from the retina and visual cortex (Laties and Sprague, 1966; Garey and Powell, 1968; Kawamura et al., 1974; Berman, 1977; Updyke, 1977; Weber and Hutchins, 1982; Koontz et al., 1985) and minor projections from the superior colliculus, ventral LGN, and accessory optic system (Swanson et al., 1974; Graham, 1977). Efferents of the pretectum include both ascending and descending pathways to a number of nuclei, especially those involved in relaying visual information to the cortex or to the oculomotor system (Berman, 1977; Itoh, 1977; Abols and Basbaum, 1979; Graybiel and Berson, 1980; Walberg et al., 1981; Robertson, 1983). The pretectum is believed to be involved in several oculomotor reflexes, including the pupillary light reflex and renexes that stabilize an image on the retina when the head or the image is in motion (Simpson et al., 1988).

Despite this general understanding of pretectal organization, many details about the function and structure of this region are lacking. Our understanding is limited in part by our very rudimentary grasp of the anatomical organization of the pretectal nuclei. The location and boundaries of individual pretectal nuclei are often difficult to delineate using conventional stains. Consequently, there has been considerable disagreement in the literature regarding the boundaries and even the number of pretectal nuclei in a variety of species (see Simpson et al., 1988, for discussion of this controversy).

The delineation of individual pretectal nuclei in the cat is further confused by recent evidence indicating that the retinal afferents form projection zones that do not respect the traditional cytoarchitecturally defined boundaries of the pretectum. Koontz et al. (1985) have shown that the retinorecipient areas of the cat pretectum form four zones that run the rostrocaudal length of the pretectum in a medial-to-lateral direction. Some of these zones appear to cross nuclear boundaries and to project through portions of the OPN, the PPN and the NOT (Koontz et al., 1985). Because the retina is a major source of input to the pretectum, a better understanding of the morphology and connections of neurons within the retinal projection zones would improve our overall understanding of the pretectal complex. In addition, it would be of great value to find a specific marker of 
pretectal neurons that corresponded to either the afferent or the efferent innervation patterns found in this visual structure.

We now report that antibodies directed against the calciumbinding protein calbindin-D $28 \mathrm{~K}$ (CaBP) label four specific cell clusters within the cat pretectal complex. These clusters form elongated zones that match the retinal recipient zones. Antibodies to calbindin previously have been shown to label select subpopulations of neurons in other regions of the CNS, including several visual-system structures (Stichel et al., 1986, 1987; Röhrenbeck et al., 1987; DeFelipe et al., 1989; Hendry et al., 1989; Jones and Hendry, 1989; Celio, 1990; Van Brederode et al., 1990; Mize et al., 1991). However, to our knowledge, this is the first example where a calcium-binding protein has labeled neurons that so precisely overlap in spatial distribution a specific afferent input. We also show that many of the neurons within the CaBP clusters project to the LGN, and that they do not colocalize the inhibitory neurotransmitter GABA.

Portions of this work have been reported previously in short communication (Nabors and Mize, 1990).

\section{Materials and Methods}

Materials. Two calbindin antisera were used, one raised in sheep from HPLC-purified calbindin-D 28K obtained from chick intestine (from Dr. Piers Emson, MRC Group, Campbridge, England), the other raised in mouse also against CaBP purified from chick intestine (obtained commercially from Sigma Chemical Co., St. Louis, MO). Two GABA antisera were used, one raised in rabbit against bovine serum albuminconjugated GABA (from Dr. Robert Wenthold, NIH; Wenthold et al., 1986) and the other raised in guinea pig against limulus hemocyaninconjugated GABA (Eugene Tech, Allendale, NJ). Vectastain AvidinBiotin-Complex $(\mathrm{ABC})$ Elite kits, the biotinylated secondary IgG antibodies, and the normal sera were obtained from Vector Laboratories (Burlingame, CA). Auroprobe streptavidin immunogold G5 (Janssen/ Amersham Corporation) was intensified with a light microscopy silver enhancement kit (Goldmark DPC, Phillipsburg, NJ). Peroxidase antiperoxidase (PAP) and a rabbit anti-mouse linking antibody were obtained from DAKO (Carpinteria, CA). The chromagen 3,3'-diaminobenzidine tetrahydrochloride (DAB) was obtained from Fluka AG (Switzerland) or Aldrich Chemical (Milwaukee, WI).

Animals, surgery, and anesthesia. A total of 19 adult cats were used in this study. Five cats were used to label retinal terminals anterogradely. These animals received intravitreal injections into the right eye of 50 $90 \mu \mathrm{l}$ of $50-70 \%$ horseradish peroxidase (HRP, Boeringer Mannheim) and $5 \%$ dimethyl sulfoxide (DMSO) dissolved in distilled $\mathrm{H}_{2} \mathrm{O}$. Seven cats were used to label pretectal projection neurons retrogradely from the lateral geniculate nucleus (LGN; $N=4$ ) or the inferior olive (IO); $N=3$ ). These cats received $0.3-0.6-\mu 1$ injections of $30 \% \mathrm{HRP}$ in distilled $\mathrm{H}_{2} \mathrm{O}$ delivered through a 5- $\mu$ l Hamilton microsyringe stereotaxically positioned with a Kopf stercotaxic apparatus. The cats survived 48-72 hr for anterograde and $24-48 \mathrm{hr}$ for retrograde transport experiments. During perfusion, the animals were anesthetized with ketamine hydrochloride-xylazine $(35 \mathrm{mg} / \mathrm{kg})$, artificially respirated with $95 \% \mathrm{O}_{2} / 5 \%$ $\mathrm{CO}_{2}$, injected intracardially with $1 \mathrm{ml}$ of $1 \%$ sodium nitrite and 1000 $U$ sodium heparin, and transcardially perfused with $250-500 \mathrm{ml}$ PBS followed by $1500-1800 \mathrm{ml}$ of a $4 \%$ paraformaldehyde- $-0.1 \%$ glutaraldehyde fixative in $0.1 \mathrm{~m}$ phosphate buffer $(\mathrm{pH} 7.4)$ with $\mathrm{CaCl}_{2}$ added. The brain was then removed and allowed to sit in fixative for 3-5 hr and then overnight in a phosphate-buffered glucose solution. The pretectum was blocked from the rest of the brain and cut into $50-\mu \mathrm{m}$ sections on a vibratome for light microscope analysis.

$H R P$ histochemistry. Anterogradely transported HRP was visualized using stabilized tetramethylbenzidine (TMB; Rye et al., 1984). Briefly, sections were rinsed six times in ice-cold distilled water and then rinsed for $20 \mathrm{~min}$ in a mixture of solutions $\mathrm{A}$ and $\mathbf{B}$ (solution $\mathrm{A}$ was made with $92.5 \mathrm{ml}$ distilled $\mathrm{H}_{2} \mathrm{O}, 100 \mathrm{mg}$ sodium nitroprusside, and $5 \mathrm{ml} 0.2$ M sodium acetate buffer, $\mathrm{pH} 3.3$; solution B was made up of $5 \mathrm{mg}$ TMB in $2.5 \mathrm{ml}$ of $100 \%$ absolute alcohol). The enzymatic reaction was initiated by the addition of $300 \mu \mathrm{l}$ of $0.3 \% \mathrm{H}_{2} \mathrm{O}_{2}$ for an additional $20 \mathrm{~min}$. Sections were then rinsed for $30 \mathrm{sec}$ in $0.1 \mathrm{M}$ phosphate buffer ( $\mathrm{pH} 6.0$ ) and placed in an ice-cold stabilizing solution composed of $5 \%$ ammonium molybdate in $0.1 \mathrm{M}$ phosphate buffer ( $\mathrm{pH} 6.0$ ) for $20 \mathrm{~min}$. Sections were then rinsed for $30 \mathrm{sec}$ and further stabilized with a $0.05 \%$ cobalt acetate-intensified DAB solution for $5 \mathrm{~min}$. The sections were then rinsed five times in cold PBS and processed further for immunocytochemistry. Retrogradely transported HRP was visualized with a cobaltintensified DAB reaction (Adams, 1981). Sections were incubated for $10 \mathrm{~min}$ in $0.05 \% \mathrm{DAB}$ to which $50 \mu \mathrm{l}$ of $1 \%$ nickel chloride/cobalt acetate $(\mathrm{NiCl} / \mathrm{CoAc})$ were added per $10 \mathrm{ml}$ of DAB solution. Sections were next incubated for $15-30 \mathrm{~min}$ in the same $0.05 \% \mathrm{DAB} \mathrm{NiCl} / \mathrm{CoAc}$ solution to which $30 \mu \mathrm{l}$ of $3 \%$ hydrogen peroxide was added per $10 \mathrm{ml}$ of the DAB solution. The crystalline black reaction product produced by the cobalt-intensified DAB procedures could be easily distinguished from the diffuse brown DAB reaction product used for antibody immunocytochemistry.

Immunocytochemistry. The avidin-biotin complex (ABC) technique was used to visualize the antibodics. Sections were collected in phosphate-buffered saline (PBS) and then incubated in 1\% sodium borohydride $\left(\mathrm{NaBH}_{4}\right)$ for $30 \mathrm{~min}$. They were then rinsed three times in PBS, blocked with $4 \%$ normal horse serum for $30 \mathrm{~min}$, and incubated in primary antibody overnight. Antibody concentrations were 1:2500 for the sheep CaBP, 1:400 for the mouse CaBP, 1:500 for the NIH GABA and 1:2000 for the Eugene Tech GABA. After incubation for 14-16 hr in the primary antibody, sections were rinsed three times with PBS, blocked with $4 \%$ normal horse serum for $30 \mathrm{~min}$, and incubated in the appropriate biotinylated secondary antibody for $30 \mathrm{~min}$. Sections were again rinsed three times with PBS and then incubated in $A B C$ for $1 \mathrm{hr}$. Finally, sections were rinsed three times with PBS and incubated in a $0.05 \% \mathrm{DAB}$ solution with $0.003 \%$ hydrogen peroxide for $30 \mathrm{sec}$ to 2 min. The sections were then rinsed three times with PBS, dried on microscope slides, dehydrated through a scrics of alcohol rinses, and coverslipped.

Two-antigen double-labeling technique. The detailed protocol and controls for this method have been reported elsewhere (Mize et al., 1991). Briefly, sections were treated first with either the GABA or CaBP antibodies, followed by a $30-\mathrm{min}$ incubation in the appropriate secondary antibody. Sections were then incubated for $1 \mathrm{hr}$ in streptavidin immunogold diluted $1: 100$ in 1\% Normal Horse Serum in PBS and then intensified with the LMSE silver enhancement kit for 5-7 min The sections were then incubated in an avidin/biotin blocking agent to block unreacted sites and then placed into the second primary antibody. When $\mathrm{CaBP}$ was used as the first primary antibody, GABA was localized using $A B C / D A B$. When GABA was used as the first primary antibody, $\mathrm{CaBP}$ was localized using the peroxidase-anti-peroxidase (PAP) procedure. The tissue was reacted with the PAP complex for $1 \mathrm{hr}$ at a dilution of 1:50.

Cell measurements. The sizes of CaBP- and GABA-immunoreactive neurons were measured with a Joyce-Loebl Magiscan MD Image Analyzer using a technique described previously (Mize, 1989). CaBP-immunoreactive cells were measured in 15 sections from one animal; GABA labeled neurons, from 12 sections in two animals. Each labeled neuron was imaged with a Dage Newvicon TV camera attached to a Nikon Microphot FX microscope at an approximate magnification of $800 \times$. The outer contour of the cell soma was traced with a light pen directly on the CRT monitor of the image analyzer to measure its crosssectional area.

Serial-section reconstructions. A neuron tracing system (NTS; Eutectic Electronics, Raleigh, NC) was used to reconstruct the calbindin cell clusters serially using a technique described by Capowski (1989). Sequential sections through the pretectum were drawn by moving the microscope stage with a joy stick so that an electronically generated cursor passed over the outer boundary of each section. The outlines of the CaBP-immunoreactive cell clusters were then traced, and the positions of all CaBP labeled cells were plotted with the system. We mapped 21 or 22 sections from two animals, each section approximately 100 $\mu \mathrm{m}$ apart. The reconstructed sections were then displayed at various angles of rotation with hidden lines removed and plotted on a digital plotter.

\section{Results}

\section{Distribution of anti-calbindin neurons}

Calbindin-immunoreactive neurons within the pretectum formed four distinct cell clusters (Fig. 1). These cell clusters were discrete areas of immunoreactivity consisting of labeled cell bodies, dendritic processes, and diffuse reaction product in the neuropil (Figs. 1, 2). An obvious boundary existed between each im- 

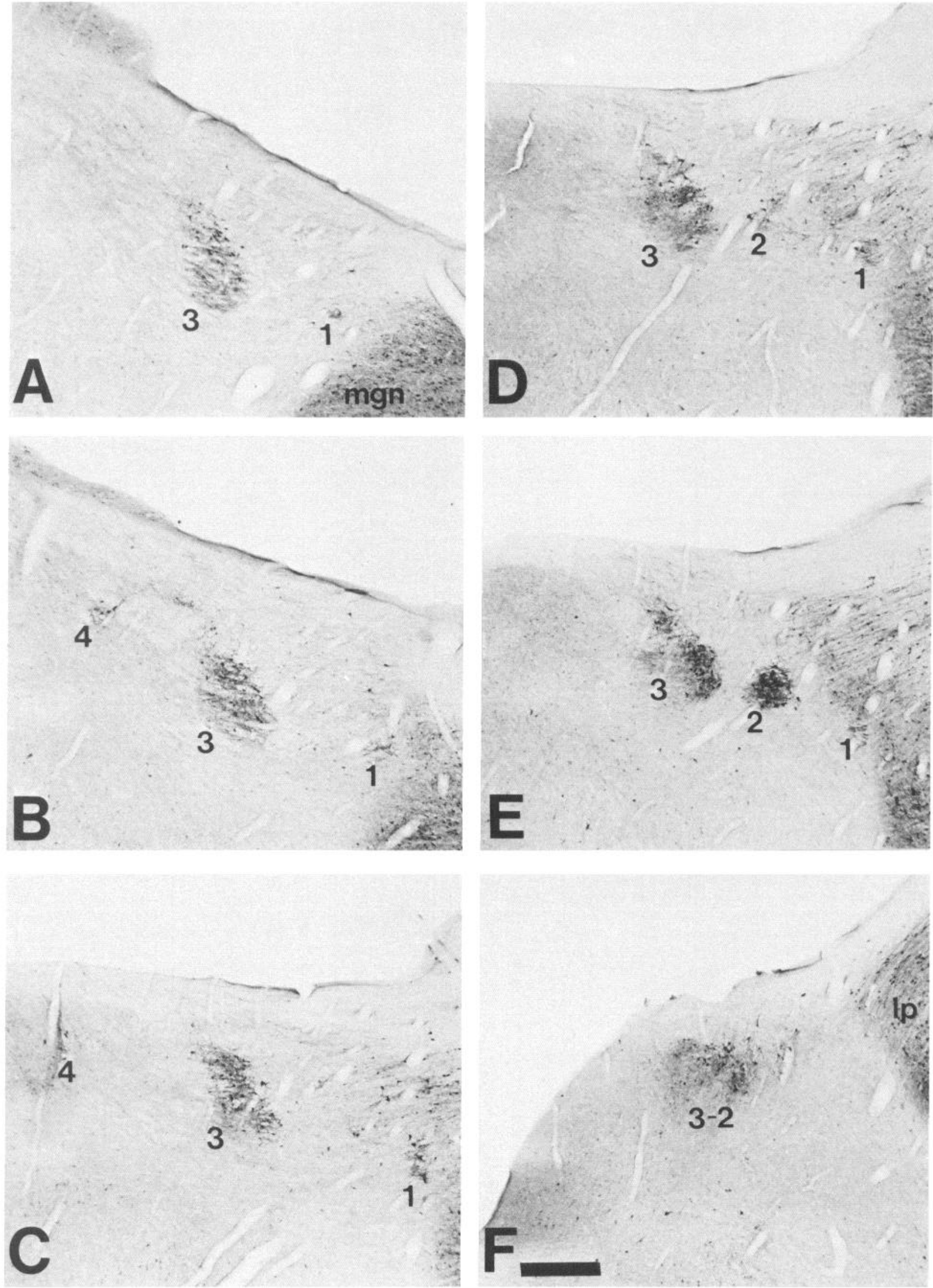

Figure 1. Four CaBP-labeled cell clusters within the cat pretectum. The clusters are numbered $1-4$ from lateral to medial after the convention of Koontz et al. (1985) for the four retinal projection zones found in the cat pretectum. Note that the clusters include both immunoreactive neurons and neuropil. Each cluster has a clearly defined boundary separating it from surrounding unlabeled neuropil. $m g n$, medial geniculate nucleus; $l p$, lateral posterior nucleus. Scale bar, $500 \mu \mathrm{m}$. 


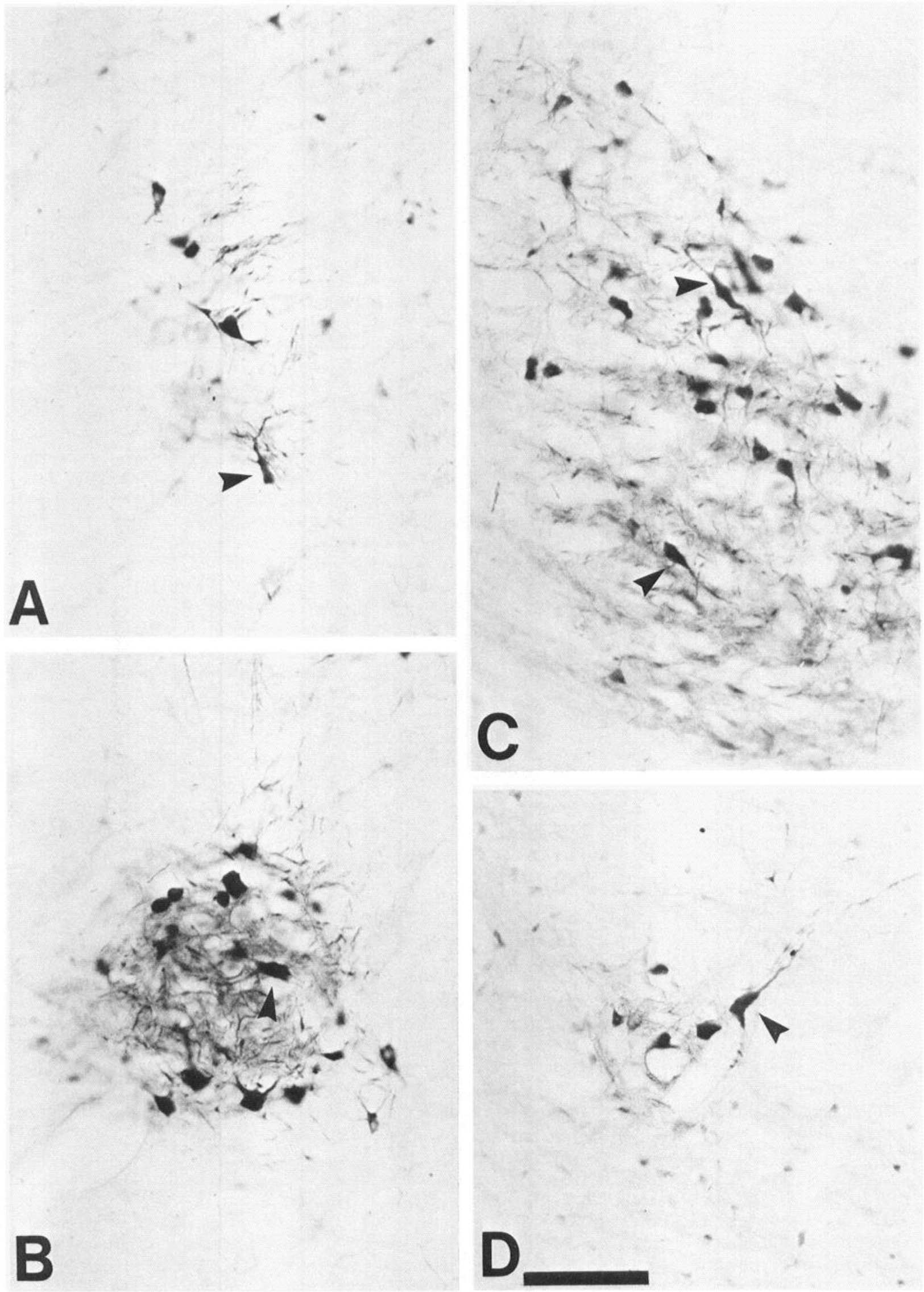

Figure 2. Higher-magnification views of representative cross sections through each of the four CaBP-immunoreactive cell clusters. $A-D$ show clusters $1-4$, respectively. Note that the clusters include heavily labeled neuronal somata, proximal dendrites (arrowheads), and some diffuse immunoreactivity that defines the boundary of each cluster. Scale bar, $100 \mu \mathrm{m}$. 

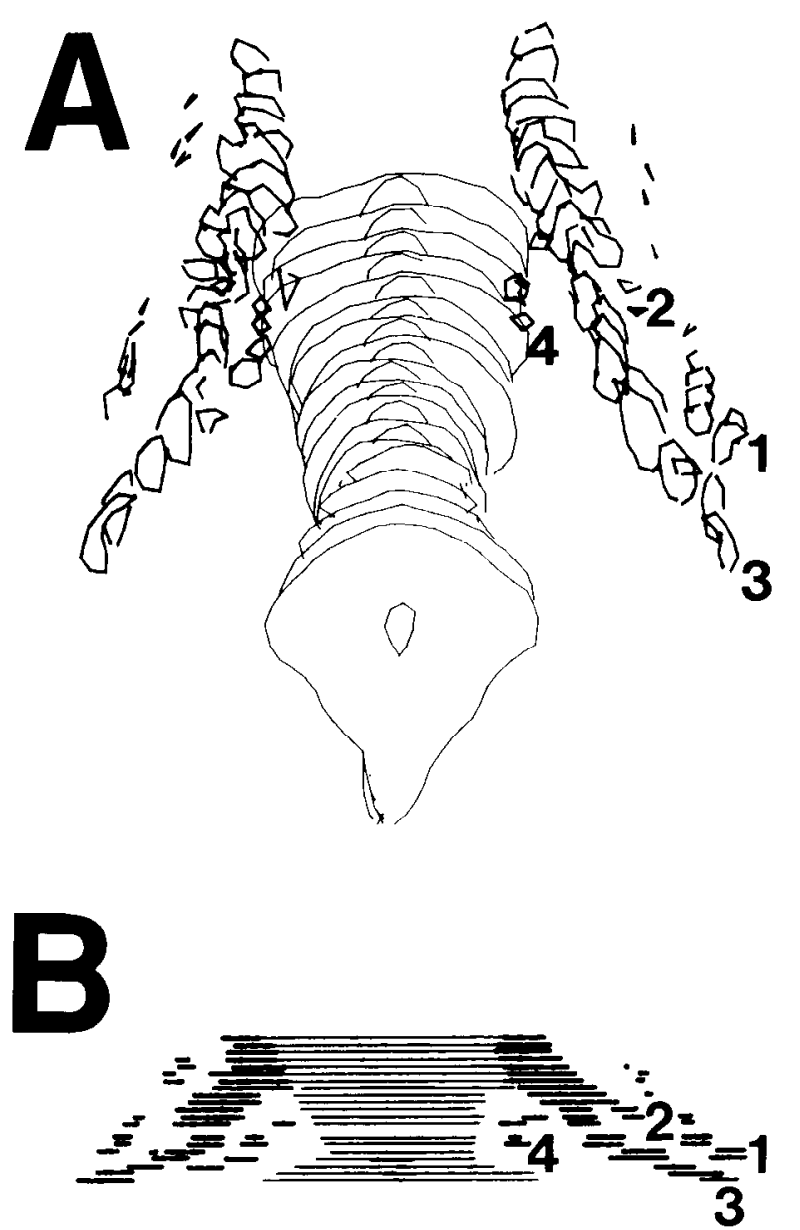

Figure 3. A, Serial-section reconstruction of the CaBP-immunoreactive cell clusters $(1-4)$ from 21 sections through the pretectum. The boundary of each cluster is outlined in relation to the periaquaductal gray and central canal. $B, A$ horizontal view of the same reconstruction rotated approximately $90^{\circ}$ by the NTS computer to illustrate the continuity of the four CaBP-immunoreactive cell clusters. The pattern of these clusters closely resembles the retinal projection zones first described by Koontz et al. (1985).

munoreactive cluster and the surrounding tissue so that it was clear that the clusters represented separate cell groups (Figs. 1, 2). We numbered these clusters from 1 to 4 in a lateral-to-medial direction after the convention of Koontz et al. (1985). Cluster 1 was a small group of cells just adjacent to the medial geniculate nucleus (Fig. 1). It formed a thin, vertically elongated band of neurons in caudal sections (Figs. $1 C, 2 A$ ) and a broader cluster in rostral sections (Fig. $1 D, E$ ). Cluster 2 was a discrete round bundle of labeled neurons found principally in mid and rostral sections of the pretectum (Fig. $1 E, 2 B$ ). Cluster 3 was the largest cluster and had an inverted comma shape through much of the rostrocaudal extent of the pretectum (Figs. 1, 2C). Cluster 4 was the smallest cluster and included only a few neurons in any given section (Fig. 2D). This cluster was found only in mid and caudal sections through the pretectum (Fig. $1 A-C$ ).

In addition to these obvious CaBP clusters, a few CaBPlabeled neurons were also randomly scattered throughout the pretectal region. Some of these sparsely distributed neurons were loosely aggregated into cell groups that appeared to lie within the medial pretectal and anterior pretectal nuclei (as defined by Kanaseki and Sprague, 1974) and the nucleus of the posterior commissure. However, these neuron groups had indistinct boundarics and never formed clusters as obvious as clusters 14. Their relationship to individual nuclei was tenuous, and we were never certain that they represented separate cell groups.

In order to gain a better understanding of the organization of the four CaBP cell clusters, we examined two series of consecutive sections cut through the entire rostrocaudal extent of the pretectum of two cats. The clusters were reconstructed in three dimensions with the NTS computer system (Fig. 3A). When rotated horizontally, the reconstructions showed that the clusters formed four nearly continuous zones that extended through the pretectum in a caudolateral-to-rostromedial direction (Fig. $3 A, B)$. Zone 1 was most lateral. It extended the full length of the pretectum, though it was occasionally interrupted by fibers of the brachium of the superior colliculus at mid pretectal levels (Fig. 3A,B). It ended caudally just lateral to the rostral superior colliculus. Zone 2 began as a separate zone at mid pretectal levels (Fig. $3 B$ ) but merged with zonc 3 in the rostral pretectum. Zone 3 extended the full length of the pretectum. It began caudally just lateral to the rostral superior colliculus and extended rostromedially (Fig. 3B), where it merged with zone 2 to form a single large labeled cell group in rostral sections (Fig. $1 F, 3 B$ ). Zone 4 was most medial. It began caudally just beneath the rostral superior colliculus and continued rostrally until it terminated at mid pretectal levels (Fig. $3 B$ ). Thus, each of the zones formed nearly continuous bands of cells that extended from caudolateral to rostromedial through the pretectum.

The relationship of these CaBP zones to traditionally defined pretectal nuclei was not obvious. Zone 1 appeared to lie within a portion of the lateral nucleus of the optic tract, as defined by Avendano and Juretschke (1980). The rostral portions of zones 2 and 3 were located within the olivary pretectal nucleus (Kanaseki and Sprague, 1974). However, in more caudal sections, zone 3 appeared to lie within the PPN, and zone 2, within the medial nucleus of the optic tract. The relation of zone 4 to specific pretectal nuclei was unclear, though a portion of this zone also appeared to lie within the PPN. Examination of adjacent coronal sections of the pretectum labeled with thionin showed no clear nuclear groups that exactly overlapped the CaBP cell clusters.

\section{Relation of the CaBP clusters to retinal terminal fields}

The zones of CaBP labeling reported above are reminiscent of the zones of retinal fiber termination described by Koontz et al. (1985) in the cat pretectum. To study directly the relationship between retinal projection zones and the CaBP cell clusters, we examined sequential sections through the pretectum in five cats that were labeled both by the anterograde transport of HRP from retinal ganglion cells and by CaBP immunocytochemistry. Significant anterograde label was found after intravitreal injections into the right eye of two of these cats. The retinal terminal labeling found in the pretectum was similar to that reported in earlier studies using HRP or tritiated amino acid anterograde transport (Berman, 1977; Hoffmann et al., 1984; Hutchins and Weber, 1985; Koontz et al., 1985). The anterograde label was found in several discrete patches within the pretectum. In rostral sections, these retinal patches perfectly overlapped the CaBP clusters (Fig. 4). Virtually no retinal terminal labeling was seen outside the clusters, and the pattern of terminal labeling was almost completely superimposed over the outline of the cell clusters in both zone 1 (Fig. $4 A$ ) and the merged zones 2 and 3 (Fig. $4 B$ ). At mid rostral levels, where zones 2 and 3 were clearly separated, light retinal label was distributed throughout the cluster of zone 2, while heavy retinal label was found in the ventral 

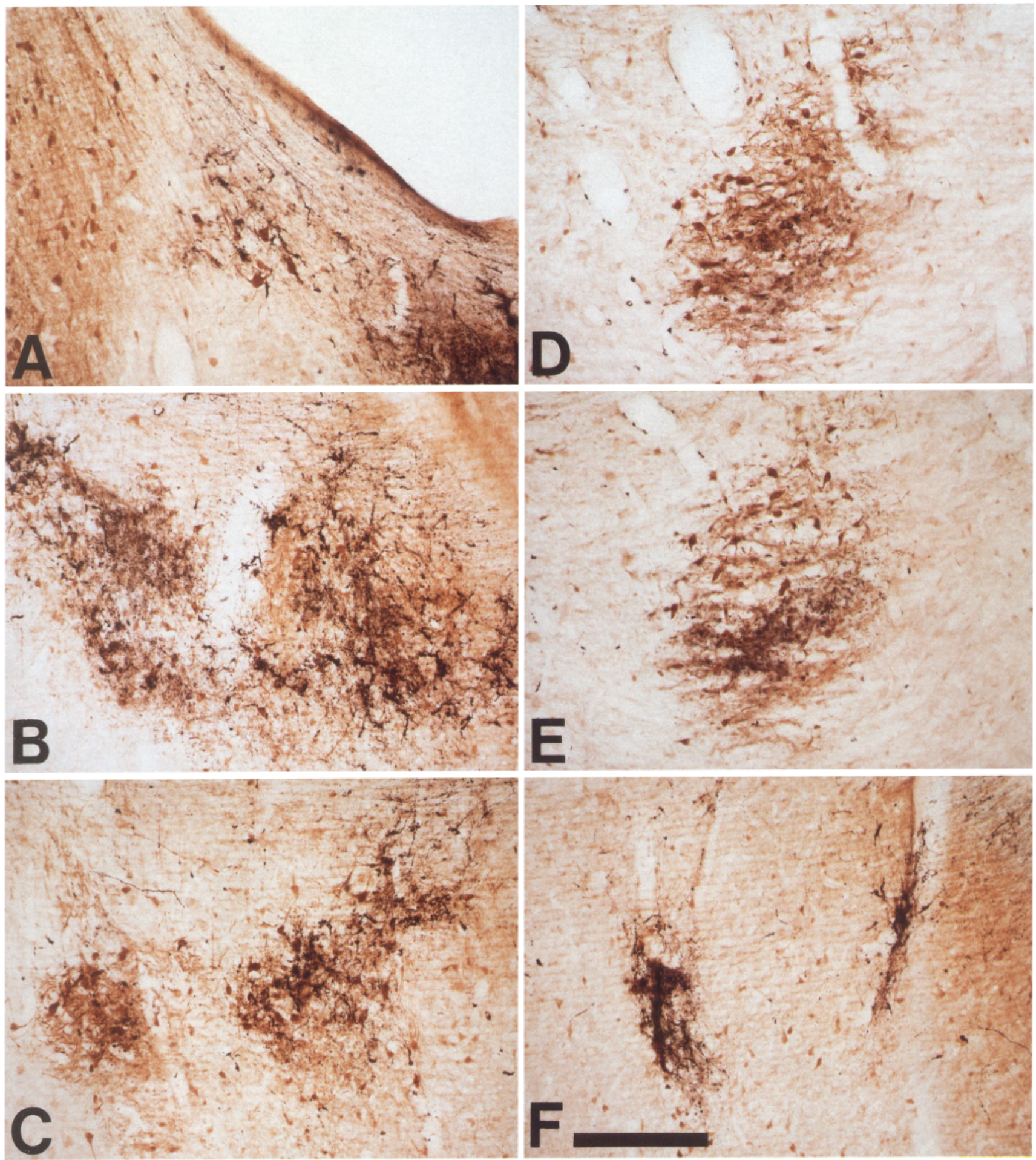

Figure 4. Representative coronal cross sections through each of the CaBP cell clusters showing the relationship between the clustered cells (brown immunoreactivity) and the distribution of contralateral retinal terminals (black reaction product). $A$, Zone 1 (lateral) and a portion of merged zones 2-3 (medial) in the rostral pretectum. B, Partially merged zones 2 (lateral) and 3 (medial). $C$, Zones 2 and 3 separated at mid rostral levels of the pretectum. $D$ and $E$, Zone 3 at mid and caudal levels. $F$, Two patches of label in zone 4 . Note that little or no retinal labeling is present outside the clusters. Left is lateral and right is medial in each micrograph. Scale bar, $250 \mu \mathrm{m}$.

region and light label in the dorsal region of zone 3 (Fig. 4C). In midcaudal sections, moderate retinal terminal labeling was found in the ventral region of zone 3 , while light labeling was found in the dorsal portions of the zone (Fig. 4D). In the most caudal sections, moderate label was found in the ventral sector of zone 3 (Fig. $4 E$ ) and very light label within the caudal extension of zone 1. Very dense retinal label was found within zone 4 (Fig. $4 F$ ), again very closely matching the outline of the 

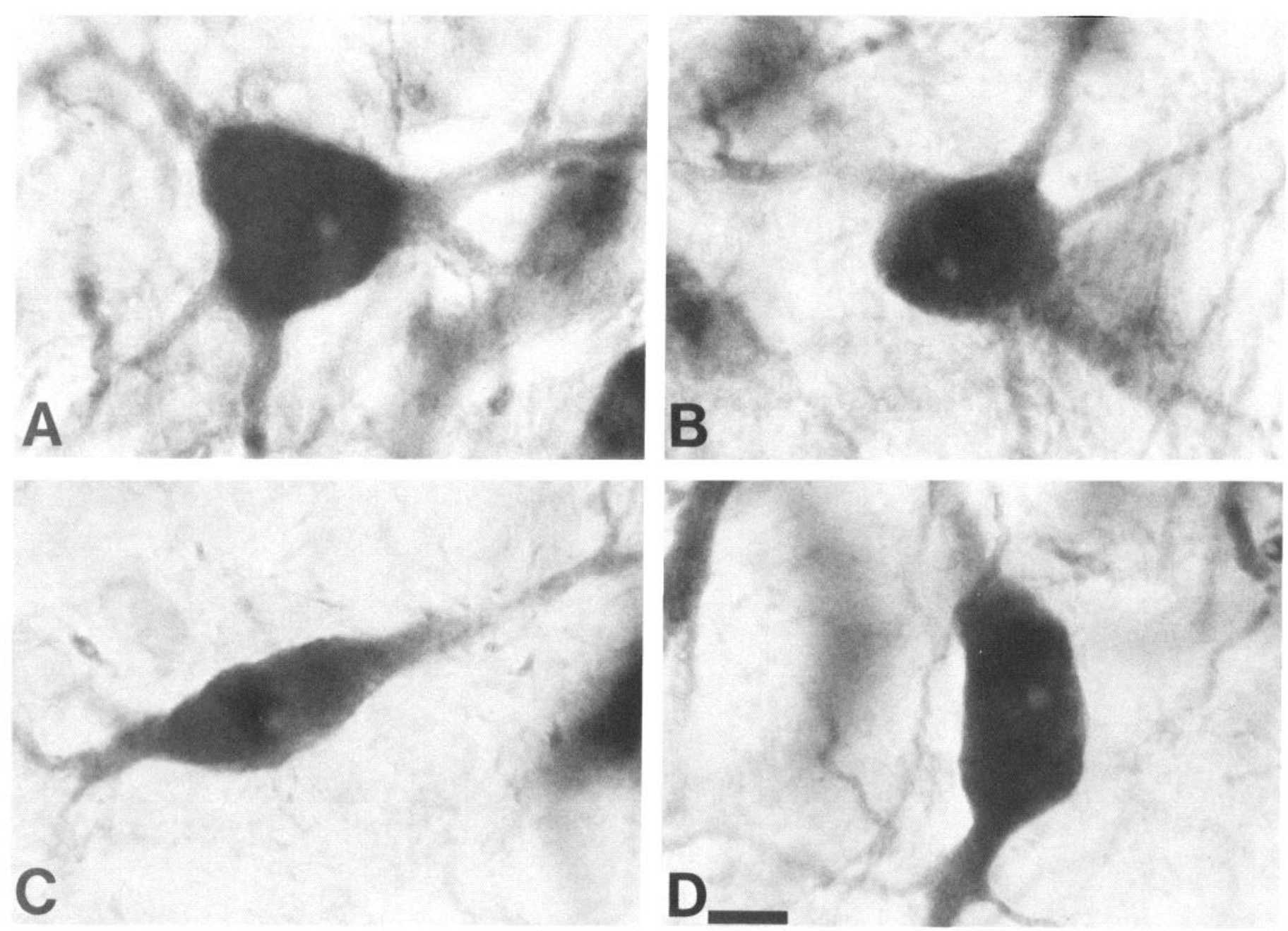

Figure 5. Morphology of CaBP-immunoreactive neurons in the cat pretectum. $A$ and $B$, Typical multipolar stellatelike neurons found frequently in clusters $1-4$. Note the large round or stellate somatas and multiple dendrites. $C$ and $D$, Fusiform neurons with elongated somatas and fewer dendrites. Note that the long axis of the fusiform cells was varied in orientation. Scale bar, $20 \mu \mathrm{m}$.

clustered cells. In two sections, a fifth zone of retinal label was observed located medial to zone 4 (Fig. $4 F$ ). Although this zone was only visible in two sections, CaBP-immunoreactive neurons were found underneath the retinal label in both sections. Thus, the retinal terminal labeling perfectly overlapped the CaBP cell clusters in rostral and middle sections through the pretectum and partially overlapped them in the most caudal sections.

Despite the incomplete labeling found in portions of the caudal CaBP cell clusters, we believe that the retinal terminal distribution in the pretectum exactly matches the boundaries of these clusters. First, no retinal terminal labeling was found outside the CaBP cell clusters except for fiber labeling within the lateral and medial brachia of the superior colliculus. Second, in the best-labeled sections, the patches of retinal terminal labeling very precisely matched the boundaries of the $\mathrm{CaBP}$ cell clusters. The CaBP and retinal terminal labeling were perfectly superimposed. Third, the reduction of retinal labeling in portions of the CaBP cell clusters in more caudal sections corresponded to incomplete labeling of the retina as ascertained by the incomplete pattern of retinal labeling in the LGN and superior colliculus. Even where the retinal terminal labeling was incomplete, it remained centered over the CaBP clusters, and no retinal terminal labeling was seen outside the clusters even in the most caudal sections (Fig. $4 E, F$ ). Finally, the zones of calbindin immunoreactivity reconstructed in this study very closely resemble the zones of retinal labeling reconstructed by Koontz et al. (1985; cf. their Fig. 3 with Fig. 3 the present article). We thus conclude that the zones formed by $\mathrm{CaBP}$ immunoreactivity match the zones of retinal terminal labeling found in the cat pretectum.

\section{Morphology of calbindin neurons}

The CaBP-labeled neurons in the clusters varied in size, but most were medium- to large-sized cells. Taken as a total population, CaBP-labeled neurons ranged in cross-sectional area from 79.3 to $774.3 \mu \mathrm{m}^{2}$, with a mean of $270.0 \mu \mathrm{m}^{2}$ (approximate average diameter of $23 \mu \mathrm{m}$ ). When we compared cell size among individual clusters, little difference was found between clusters 1,2 , and 3. CaBP-labeled neurons in cluster 4 were smaller with a mean area of $184 \mu \mathrm{m}^{2}$.

The CaBP-labeled neurons in the clusters also varied in morphology. CaBP immunoreactivity was seen throughout the cell soma and extended well into the dendritic processes. The nucleolus was not labeled, but the nucleus was heavily labeled in these neurons (Fig. 5). Labeled processes sometimes could be 

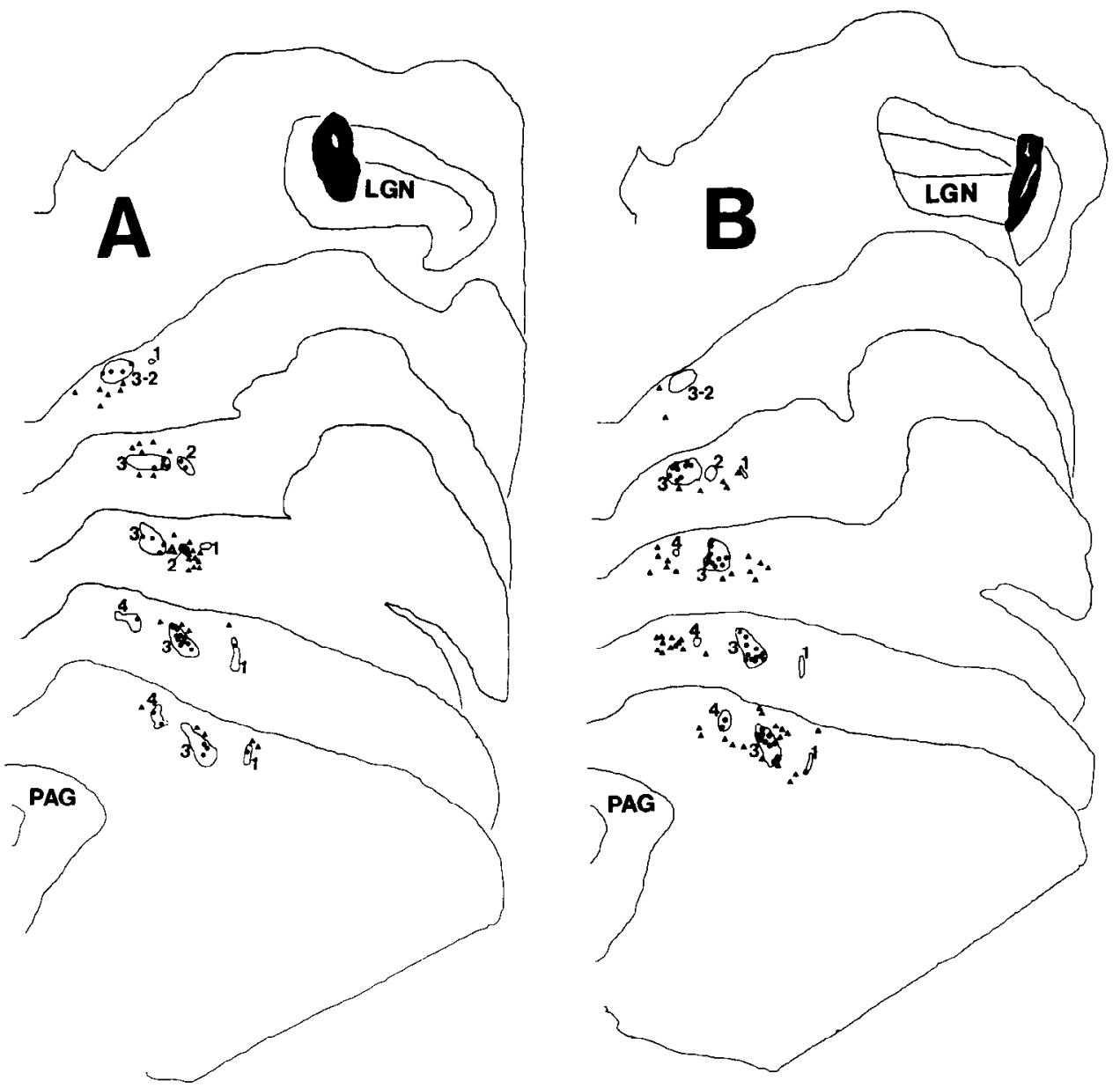

Figure 6. $A$ and $B$, Computer reconstructions of the distribution of HRPfilled (triangles) and HRP plus $\mathrm{CaBP}$ double-labeled neurons (circles) in the cat pretectum. Note that there are many HRP-filled neurons that he outside the CaBP cell clusters (1-4), while all double-labeled neurons are found within the clusters. $A$ illustrates an HRP injection into the medial LGN; $B$, an injection into the lateral dLGN that also invaded the medial ventral LGN. $P A G$, periaquaductal gray. traced out to secondary and tertiary dendritic branches, so that the detailed morphology of these neurons was visible. CaBPlabeled neurons included at least two distinct morphologies. Many of the labeled neurons were multipolar cells with round or stellatelike cell bodies and multiple, highly branched dendrites (Fig. $5 A, B$ ). In these cells, the dendrites radiated in all directions from the somata. Other neurons had fusiform somata and two prominent dendrites emanating from either pole of the cell body (Fig. 5C,D). The orientation of these elongated fusiform cell bodies varied, though in cluster 3 the dendrites usually ran parallel to the vertical axis of the cluster. Multipolar neurons were much more common than fusiform ncurons in all four CaBP cell clusters.

\section{Calbindin-immunoreactive projection neurons}

The calbindin-immunoreactive neurons in the pretectum were similar in size and morphology to the projection neurons described in this structure. Two of the principal targets of pretectal projection neurons in the cat are the LGN and the IO (Berman, 1977; Graybiel and Berson, 1980; Walberg et al., 1981; Kubota et al., 1987). To determine directly whether CaBP-immunoreactive neurons were projection neurons, we injected HRP into these two targets and looked for neurons labeled by both HRP and $\mathrm{CaBP}$.

Six injections were made into the LGN of four cats. Two of these injections were centered within the dorsal layers of the dLGN. One was located medially at mid rostrocaudal levels of the dLGN (Fig. 6A). The other injection was located laterally and involved principally the monocular segment of lamina $A$ and the medial most portion of the ventral LGN (Fig. 6B). A third injection was located caudally and more heavily involved the ventral parvicellular layers, though some dorsal-layer labeling was also present. Of the three other injections, one missed the LGN entirely, one hit only the ventral LGN, and one was within the dLGN but so small that it produced few retrogradely labeled neurons.

In the two experiments in which the injections were focused in the dorsal layers, retrogradely labeled neurons were found throughout much of the rostral caudal extent of the pretectum. In both experiments, HRP-labeled neurons were distributed across much of the medial-lateral extent of the pretectum both within and outside the clusters (Fig. 6). In both cases, some labeled cells were found in all four clusters, but the densest concentration of HRP cells differed somewhat for the two injections. After the medial LGN injection, large numbers of HRPlabeled cells were found in cluster 3 and within caudal cluster 2 (Fig. $6 A$ ) and very few in clusters 1 and 4 . After the lateral injection, most HRP-labeled cells were found within and surrounding cluster 3 , but there was also a second cluster of HRP labeled neurons within and medial to cluster 4 (Fig. 6B). These different distributions probably reflect the topographic organization between the pretectum and dLGN because there was a lateral-to-medial shift in distribution between the two cases $(\mathrm{Ku}$ bota et al., 1987). 
Within the clusters, virtually all of the HRP labcled ncurons were also labeled by CaBP (Fig. 6, circles). The only HRP neurons not labeled by CaBP were confined to a plane of focus above or below the planes of CaBP labeling and thus did not gain access to the antibody. No HRP-labeled cells outside of the clusters were labeled with CaBP. The double-labeled neurons in the clusters included both multipolar neurons with stellate morphologies (Fig. 7 $A, B$ ) and fusiform-shaped neurons with dendrites extending from either pole of the neuron (Fig. $7 C, D$ ). Thus, the double-labeled cell population did not differ obviously in morphology from single-labeled CaBP cells.

Although all HRP-labeled cells in the clusters were CaBP immunoreactive, not all CaBP-labeled cells contained HRP. To estimate the actual percentage of CaBP-labeled cells projecting to the LGN, we measured the ratio of double-labeled to total CaBP-labeled cells in 10 sections through zone 3 of two animals. In both animals, there was a pcak percentage of double-labeled neurons in one section with decreased numbers in more rostal and more caudal sections that undoubtedly reflects the selective topographic distribution resulting from incomplete HRP filling of the LGN. In zone 3, 40-60\% of CaBP-labeled neurons were retrogradely labeled by $\mathrm{HRP}$ in the best-labeled sections. We believe that this percentage may be a reasonable estimate of the actual percentage of $\mathrm{CaBP}$-labeled neurons that project to the LGN complex.

Six injections were made into the $\mathrm{IO}$ of three cats. Two of these injections were centered within the dorsal nucleus of the rostral IO, a principal site of termination of the cat pretectum (Walberg et al., 1981). These two injections produced large numbers of labeled cells in the pretectum. The other four injections either missed the IO or were centered in other olivary nuclei and produced few retrogradely labeled neurons in the pretectal region.

No retrogradely labeled neurons were found within the $\mathrm{CaBP}$ clusters after IO injections. (Fig. 8A). HRP-filled cells were distributed along the dorsal border of the pretectum, along a medial-to-lateral strip that appears to include both portions of the OPN and the NOT (Fig. $8 A$ ). A few of those neurons appeared to be very lightly labeled by CaBP (Fig. $8 \mathrm{C}$ ), but most clearly contained no CaBP immunoreactivity (Fig. $8 B$ ). Numerous HRPfilled neurons also were distributed densely within the nucleus of Darkschewitsch, indicating that the retrograde transport of HRP was robust in these experiments. Nevertheless, we did not find a single example of an HRP-labeled neuron within any of the four CaBP cell clusters. We therefore conclude that many of the CaBP-cluster neurons project to the LGN but not to the IO.

\section{GABA-immunoreactive neurons in the cat pretectum}

Many CaBP-labeled neurons within the CNS are also GABA immunoreactive (Hendry et al., 1989; Celio 1990; Van Brederode et al., 1990). To determine if CaBP-labeled neurons in the pretectum are GABAergic, we examined the distribution, size, and morphology of GABA-labeled cells using two well-characterized antibodies to GABA. A two-color double-labeling technique was used to determine if any of these neurons also colocalized CaBP.

GABA-labeled neurons were distributed throughout the pretectum. Slightly higher densities of GABA neurons could sometimes be detected within cluster 3 . The neuropil within cluster 3 also was sometimes more immunoreactive for GABA than was the surrounding region. However, none of the clusters were as obvious in GABA-labeled material as they were using the CaBP antibody. The GABA-labeled neurons within the pretectal clusters were virtually all small cells (Fig. 9). We measured 290 GABA-labeled neurons in two animals, one treated with the NIH GABA antibody, the other with the Eugene Tech antibody. GABA-labeled neurons were measured from all four clusters, but most of the measured cells were in cluster 3 . In both animals, the GABA neurons were of similar size, ranging in area from 42.3 to $178.5 \mu \mathrm{m}^{2}$, with a mean of $93.2 \mu \mathrm{m}^{2}$ (approximate average diameter, $12 \mu \mathrm{m}$ ). GABA-labeled neurons in the pretectum were thus smaller than the vast majority of CaBP-labeled neurons (Fig. 9). The morphology of these neurons also differed from that of CaBP-labeled neurons. The GABA neurons usually had a round or slightly ovoid shape, with limited cytoplasm and few or no labeled dendrites (see Fig. 11). By contrast, CaBP neurons for the most part had larger somata with prominently labeled dendrites and stellatc or fusiform shapes.

Colocalization studies confirmed that the two populations differed. No GABA-labeled neurons were found to be immunoreactive for $\mathrm{CaBP}$ within the cell clusters. Figure 10 shows examples of GABA-immunoreactive cells labeled with silver and CaBP-immunoreactive cells labeled with DAB. Note that the cells differ in both size and shape in the three clusters illustrated. There were no double-labeled neurons in any cluster in any section examined. Very rarely, possible double-labeled neurons were observed outside the clusters. In most of these cases, the silver labeling was sparse, and it was difficult to be certain that they were double labeled. In addition, no neurons labeled by the GABA antibody were retrogradely labeled by HRP injected into either the LGN or the IO. Figure 11 shows four examples of HRP- and GABA-labeled neurons within cluster 3 of the pretectum after an HRP injection into the LGN. In each example, the HRP-labeled and GABA-labeled neurons clcarly differ in both size and morphology. GABA-labeled neurons were small, while the backfilled HRP neurons were larger with multipolar dendrites (Fig. 11). The GABA neuropil labeling was often quite dense and sometimes underlay the HRP-filled neurons in $50-\mu \mathrm{m}$-thick sections (Fig. $11 \mathrm{C}$ ). Nevertheless, when the two neuron populations were in the same focal plane, they were never double labeled. We therefore conclude that the GABA neurons within the CaBP clusters are small neurons that do not contain calbindin and do not project to the LGN or IO.

\section{Discussion}

The calcium-binding protein calbindin has proven to be a specific marker of select subpopulations of neurons in many regions of the CNS (see Celio, 1990, for a thorough survey). We have shown that calbindin also labels a unique subset of neurons in the cat pretectum. These neurons form four discrete cellular zones that match the zones of retinal input to the pretectum. Many are projection neurons to the LGN. They do not appear to colocalize GABA. This labeling pattern in the pretectum is of general interest because it reveals a specific group of neurons that apparently share an afferent input from the retina, though they cross nuclear boundaries and differ in morphology. This is one of the first examples in the brain where a postsynaptic chemical marker so precisely identifies neurons all of which appear to receive input from a specific afferent source.

Nevertheless, a number of important questions about the organization of CaBP in the pretectum must be addressed. First, are all pretectal neurons that receive retinal input labeled by $\mathrm{CaBP}$ ? Second, does CaBP label a specific class of projection 

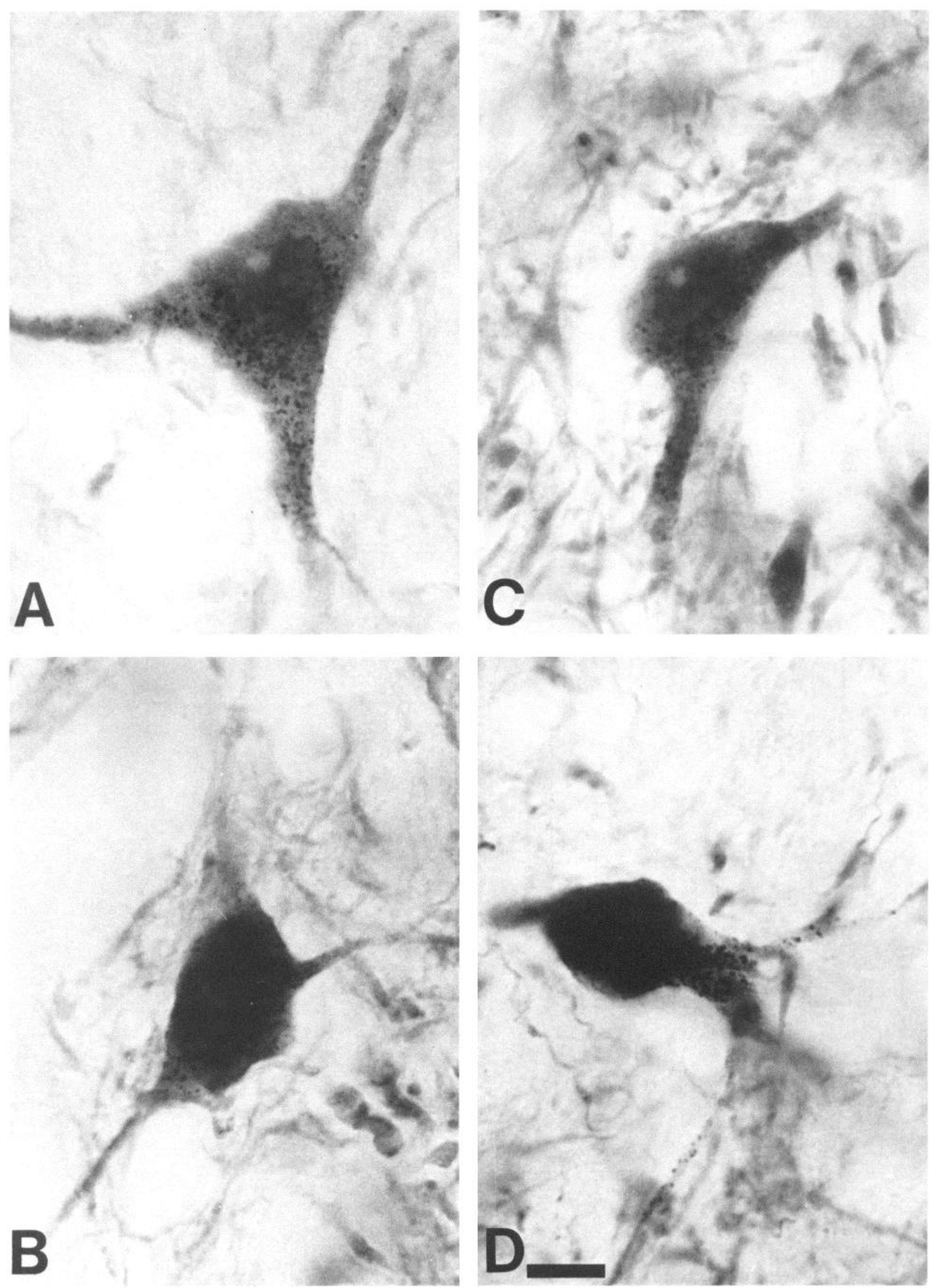

Figure 7. Morphologies of neurons retrogradely labeled by HRP injections into the LGN. Note that the cells are either multipolar stellatelike neurons $(A, B)$ or medium-sized fusiform neurons $(C, D)$. Scale bar, $20 \mu \mathrm{m}$. 

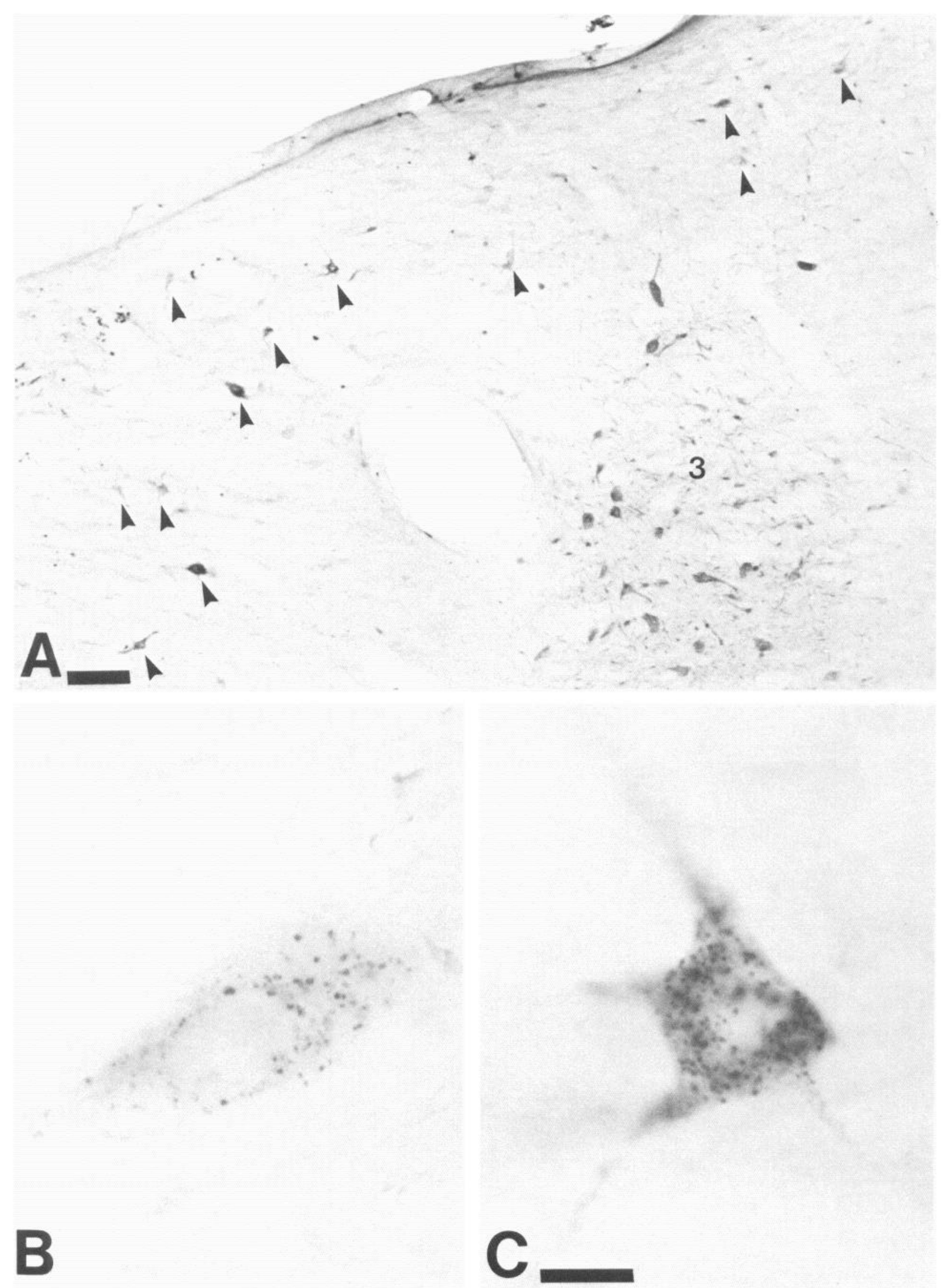

Figure 8. A, Low-magnification view of HRP-backfilled neurons (arrowheads) after an injection into the IO. Note that the HRP-filled neurons are distributed along the dorsal border of the pretectum. No HRP-filled neurons were present in cluster 3. $B$, Individual HRP-labeled neuron that was not labeled by CaBP. $C$, HRP-labeled neuron that may be lightly labeled by CaBP. Scale bars: $A, 100 \mu \mathrm{m} ; B$ and $C, 10 \mu \mathrm{m}$. 
neuron? Third, are any neurons in the CaBP cell clusters GABAergic? Fourth, do the CaBP cell clusters relate to traditionally defined pretectal nuclci? Finally, what unique function does $\mathrm{CaBP}$ play in these neurons? In short, what is the key property or properties of a pretectal neuron that determine whether it will contain calbindin? We attempt to answer these questions in the discussion that follows.

\section{Do all pretectal cluster neurons receive retinal input?}

Our combined orthograde transport-immunocytochemistry experiments show clearly that the retinal input to the pretectum is superimposed almost perfectly upon the CaBP cell clusters. In most individual sections, there was a striking overlap between retinal terminal labeling and CaBP cluster immunoreactivity. Virtually no retinal terminal labeling was found outside the clusters. In caudal sections where the terminal labeling occupied only portions of the clusters, the pattern of retinal labeling was correlated with incomplete filling of the eye with HRP. There is thus no doubt that retinal afferents to the pretectum match the CaBP cell zones. Such a precise fit between an afferent pathway and postsynaptic CaBP neurons must have important implications for the function of these cells.

The significance of the overlap is unknown. One possibility is that only neurons containing CaBP receive retinal input. This is clearly not supported by other morphological data. We have shown that the small GABA-immunoreactive neurons within the $\mathrm{CaBP}$ clusters are not labeled by $\mathrm{CaBP}$, yet electron microscope studies within the rabbit pretectum show numerous examples of retinal synapses contacting GABA-labeled processes (Van der Want and Nunes Cardozo, 1988). In the cat, retinal terminals contact presynaptic dendrites with pleomorphic synaptic vesicles (Spencer et al., 1983), which are identical to some of the GABAergic profiles found in rabbit (Van der Want and Nunes Cardozo, 1988). Thus, some neurons that do not contain $\mathrm{CaBP}$ are definitely contacted by retinal synapses.

Our results also show that scattered neurons that are labeled in the MPN, the APN, and the nucleus of the posterior commissure probably do not receive retinal input, because few or no retinal terminals end in these nuclei (Kanaseki and Sprague, 1974; Berman, 1977; Weber and Hutchins, 1982). No strict correspondence between retinal afferents and CaBP-immunoreactive neurons has been found in other subcortical visual structures. In the superior colliculus, CaBP-labeled neurons are found in three separate laminar tiers (Mize et al., 1991). Only the superficial tier overlaps the distribution of retinal terminals. Even in this tier, the correspondence is far from exact, because many neurons in the deep superficial gray whose dendrites receive direct retinal in put are not labeled by CaBP. Thus, synaptic innervation by retinal terminals is not the sole determinant of whether a pretectal cell will contain calbindin. On the other hand, the precise match of retinal terminals and CaBP neurons must have functional significance. We believe this function relates to the firing properties of CaBP cells, an idea we will discuss below.

\section{Does CaBP content define a class of projection neuron?}

If $\mathrm{CaBP}$ is not a functional marker of all retinal recipient neurons, is it restricted to a certain class of projection neuron? Our results show that many $\mathrm{CaBP}$-labeled neurons were backfilled by injections of HRP into the LGN. In some sections, as many as $60 \%$ of all CaBP neurons contained HRP. Because our LGN injections were small, it is quite possible that the CaBP cluster
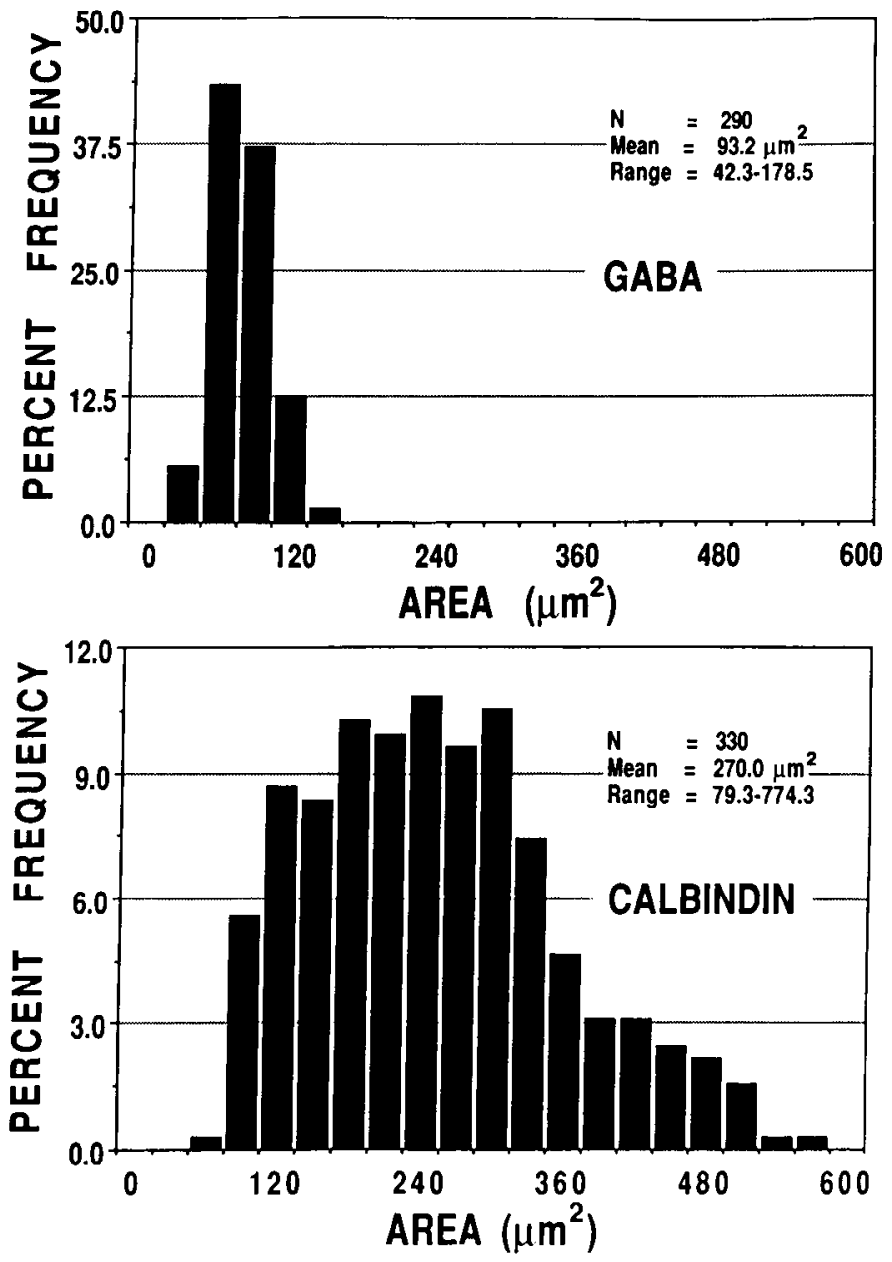

Figure 9. Top, Histogram of the cross-sectional area of 290 neurons in the four $\mathrm{CaBP}$ cell clusters of the pretectum that were labeled by GABA immunoreactivity. Bottom, For comparison, histogram of the area of $330 \mathrm{CaBP}$-labeled neurons in the pretectal cell clusters. Note that the GABA-labeled neurons are on average about one-third the size of the CaBP-labeled neurons.

neurons not labeled by HRP are other LGN-projecting neurons whose axons did not gain access to the tracer. However, LGN projection neurons lying outside the clusters were not CaBP immunoreactive. Most pretectal neurons projecting to the IO were also $\mathrm{CaBP}$ negative. Thus, only some projection neurons in the pretectum are labeled by CaBP.

This is also true in other regions of the CNS. Purkinje neurons in the cerebellum are intensely labeled by $\mathrm{CaBP}$, but Golgi neurons projecting from the granule layer to the molecular layer are not (Baimbridge and Miller, 1982; Celio, 1990). In the cat superior colliculus, a small percentage of superficial layer neurons projecting to the $\mathrm{LGN}$ are labeled by $\mathrm{CaBP}$, but many others are not, and no neurons projecting to the lateral posterior nucleus or through the descending tracts of the colliculus are CaBP immunoreactive (Mize et al., 1991). CA1-CA2 pyramidal neurons in the hippocampus are CaBP positive, but those in the CA3-CA4 region are CaBP negative (Celio, 1990). There are thus a variety of projection neuron types within the CNS that contain calbindin, but not all projection neurons in a region are CaBP labeled, and not all cells of a particular projection class are labeled. Projection per se is not an invariant determinant of whether a neuron will contain $\mathrm{CaBP}$. 

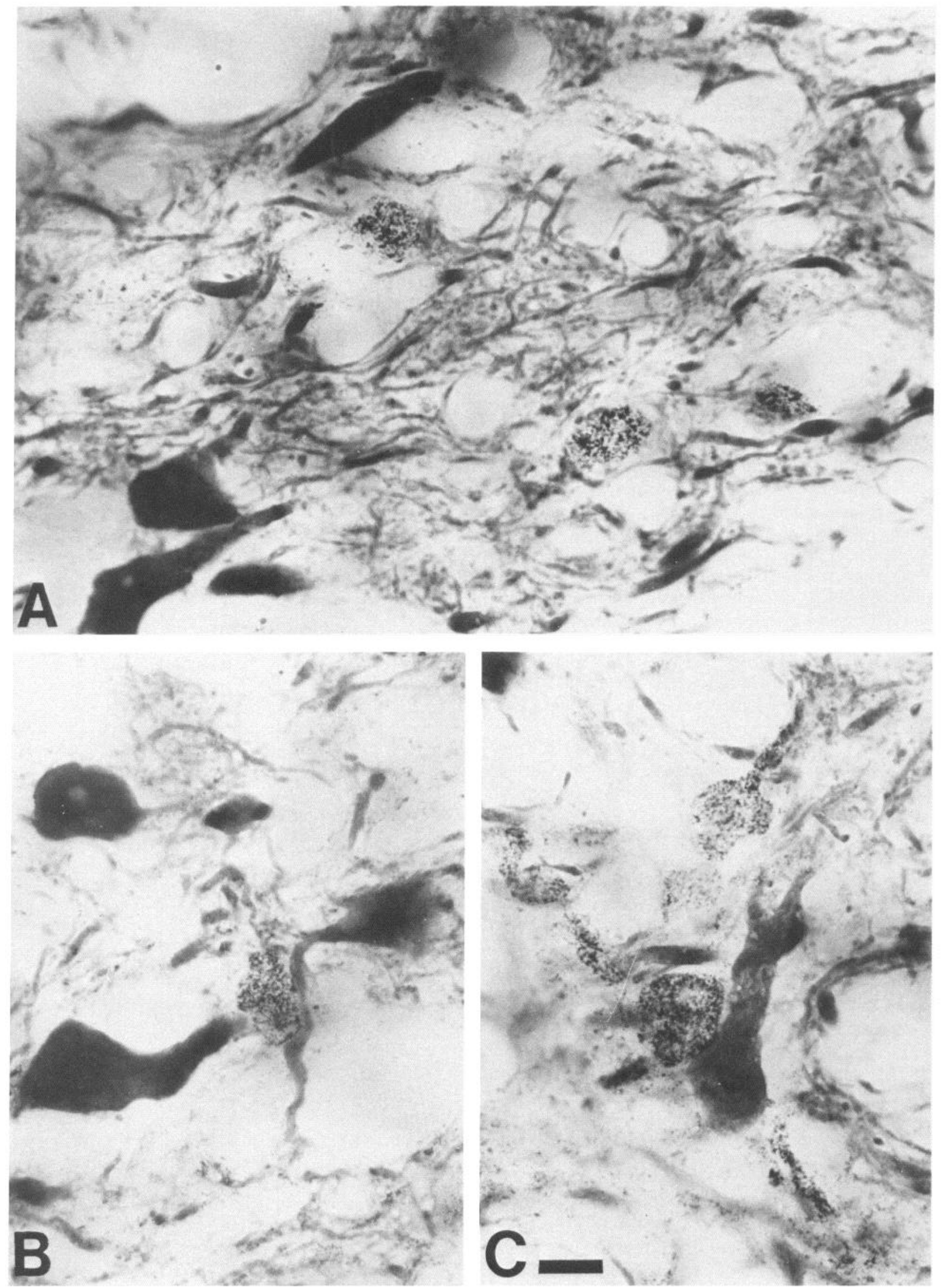

Figure 10. Morphologies of neurons labeled by anti-CaBP or GABA in the two-antibody double-label experiments. Neurons containing CaBP were visualized with DAB (diffuse dark reaction product), while neurons containing GABA were visualized with silver-intensified immunogold (black particles). Scale bar, $10 \mu \mathrm{m}$. 

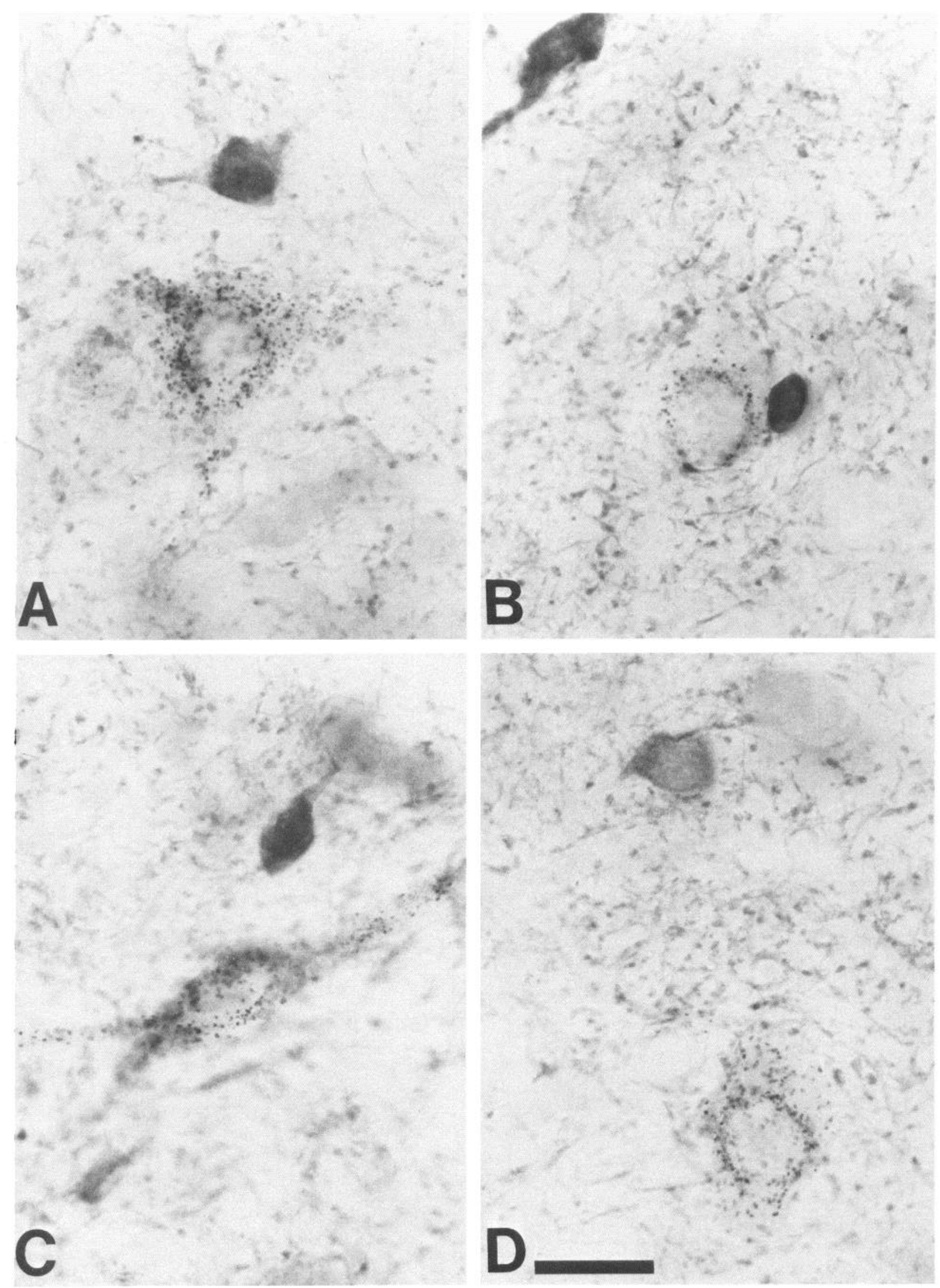

Figure 11. Neurons immunocytochemically labeled by GABA (diffuse dark reaction product) or retrogradely labeled by HRP (black particles) following injections into the LGN. Note the small size of the GABA-labeled neurons compared to the HRP-labeled cells. Scale bar, $20 \mu \mathrm{m}$. 
Are any CaBP neurons in the pretectum GABAergic?

GABA and CaBP are colocalized in individual neurons in some parts of the CNS, but not in others. Purkinje neurons are well labeled by both CaBP (Baimbridge and Miller, 1982; Celio, 1990) and GABA (for review, see Mugnaini and Oertel, 1985). The medium spiny neurons of the striatum contain both CaBP (Gerfen et al., 1985; DiFiglia et al., 1989; Celio, 1990) and glutamic acid decarboxylase (GAD; Ribak et al., 1979; Oertel and Mugnaini, 1984). Many if not all CaBP neurons in visual cortex are also labeled by GABA (DeFelipe et al., 1989; Celio, 1990; Van Brederode et al., 1990) as are at least some neurons in the LGN (Fitzpatrick et al., 1984; Stichel et al., 1986). Nevertheless, two results of our study demonstrate that CaBP neurons in the pretectal clusters are unlikely to be GABAergic. First, almost all GABA-labeled neurons were smaller than the CaBPlabeled neurons. Second, in double-label experiments, the two substances were not colocalized in any neurons within the $\mathrm{CaBP}$ clusters. We also found that GABA-labeled neurons in the clusters did not project to the LGN or IO. These results are in essential agreement with previously published studies.

In cat, GAD-positive neurons have been shown to comprise $10-20 \%$ of pretectal neurons whose mean size was smaller than the total population of Nissl-stained cells (Weber and Chen, 1984). In the cat NOT, GABA-labeled neurons were found not to project to the IO and were significantly smaller than the IO projection neurons (Horn and Hoffmann, 1987). Nunes Cardozo and Van der Want (1990) have also shown that GABA neurons in the rabbit pretectum are smaller and differ in morphology from those projecting to the IO. Reports in other species indicate that most GABAergic neurons in the pretectum are small neurons, as well (Ottersen and Storm-Mathisen, 1984; Penny et al., 1984; Giolli et al., 1985). On the other hand, a very recent study by Cucchiaro et al. (1991) reports a dramatically different result in the pretectum of cat. In their study, $40 \%$ of LGN projecting neurons in the cat pretectum were GABA immunoreactive. Further, these neurons were as large as non-GABA-projecting neurons and larger than the population of GABA-labeled neurons that did not project to the LGN (Cucchiaro et al., 1991). These authors conclude that there are probably two populations of GABA-immunoreactive neurons, one a projection neuron and one a local circuit interneuron.

How the results of Cucchiaro et al. (1991) can be resolved with the present results is unclear. One possibility is that the two studies sampled different regions of the pretectum. We focused our observations on the CaBP cell clusters. These clusters form only a portion of the region examined by Cucchiaro et al. (1991). On occasion, we did find scattered HRP back-filled neurons outside the clusters that were very lightly labeled by reaction product. These could be double-labeled neurons, though we interpreted the light brown labeling to be background. Another possibility is that the GABA antibodies used in the two studies differ in sensitivity and/or specificity. Cucchiaro et al. (1991) used an antibody produced by IncStar, while our results are based on tissue treated with the Wenthold or Eugene Tech antibodies. It may be that these latter antibodies are not as sensitive to low concentrations of GABA. Alternatively, the IncStar antibody may not be as specific for GABA. We have no final explanation for why our results differ, but it will be important to clarify this issue because Cucchiaro et al. (1991) argue that many LGN pretectal projection neurons are inhibitory, while our results suggest they are not.
Do the CaBP cell clusters relate to traditional pretectal nuclei?

We have shown that the CaBP cell clusters form four elongated but continuous cell zones that fall at least partly within the borders of the OPN, the PPN, and the NOT, as defined by Kanaseki and Sprague (1974). These CaBP cell clusters precisely overlap the retinal terminal zones found in these nuclei. However, it is not clear how these $\mathrm{CaBP}$ and retinal terminal zones relate to the cytoarchitecturally defined nuclei.

That the retinal input to the pretectum is organized into a series of parallel sheets or zones was tirst recognized by Scalia and Arango (1979) in rat. In cat, these zones of retinal input were first described by Koontz et al. (1985). However, separate clusters of retinal terminals in the cat pretectum were also recognized by Berman (1977) and Hutchins and Weber (1985) using orthograde autoradiographic transport techniques. Although the results of these studies are in essential agreement, there is little agreement about how the zones of retinal input (and thus the CaBP cell clusters) correspond to the traditionally defined boundaries of pretectal nuclei.

Berman (1977) defined the nuclei in a manner similar to that of Kanaseki and Sprague (1974). The strips of retinal label she described appear from her figures to cross the boundaries of these nuclei, though the article provides too little detail to be certain of this. Hutchins and Weber (1985) also found separate strips of retinal label in the cat pretectum. They argued that two of the fingerlike strips (our zones 2 and 3 ) are continuations of the OPN. They based this conclusion upon two observations: the continuity of the fingerlike cxtensions of retinal labeling with the retinal labeling in the main OPN and the fact that the cells in the extensions were medium-sized fusiform neurons like those in the main OPN. They also identified two lateral strips of label, one of which they identified as the NOT. These two strips probably correspond to our caudal zones 1 and 2 and may lie partly within the lateral and medial divisions of the NOT as defined by Avendano and Juretschke (1980). Several patches of medial label were designated by Hutchins and Weber (1985) as part of the PPN. These appear to be the patches we identify as zone 4 . Thus, at least some of the patches of label found by Hutchins and Weber (1985) fall within the boundaries of specific pretectal nuclei, though the extensions of the OPN field were not previously identified as part of the OPN (Kanaseki and Sprague, 1974).

Koontz et al. (1985) were the first to reconstruct carefully all four zones of retinal input and to define them as continuous zones. In their view, the relationship between the retinal zones and the conventionally defined pretectal nuclei is unclear because the nuclei are so difficult to distinguish in transverse sections using thionin stains. In fact, they point out that differences in the reports of retinal terminal innervation in the cat pretectum are largely due to differences in the identification of the pretectal nuclei and not the pattern of retinal projections. They suggested that the nuclear groups might be more clearly identified in horizontally cut sections.

Our results are directly relevant to this issue because we found continuous zones of $\mathrm{CaBP}$ labeled neurons immediately postsynaptic to the retinal terminal zones. The CaBP-labeled neurons in our study did not differ obviously in morphology in the four zones, but formed relatively continuous horizontal columns of neurons through the rostrocaudal axis of the pretectum. There were no evident distinctions that allowed us to categorize one cell type as belonging to one nucleus and another cell type to another nucleus. In addition, our data show that both zones 2 
and 3 and zones 1 and 2 probably merge into single groups of CaBP-labeled cells. We believe, therefore, that these cellular zones are probably a continuous system(s) of $\mathrm{CaBP}$ neurons that cross the nuclear boundaries of the cat pretectum as previously defined (Kanaseki and Sprague, 1974; Avendano and Juretschke, 1980). Given these results, it is important in our opinion to reexamine the conventional definitions of pretectal nuclei keeping in mind that groups of functionally similar neurons may cross traditionally defined cytoarchitectonic boundaries.

\section{What is the function of calbindin in pretectal neurons?}

Calbindin-D $28 \mathrm{~K}$ is a member of the family of calcium-binding proteins that regulate intracellular calcium in cells. It is thought that calbindin acts either as an intracellular calcium buffer (Baimbridge and Miller, 1982; Heizmann and Berchtold, 1987) or in the transport of calcium across the cell membrane (Wasserman and Fullmer, 1982; Bronner et al., 1986). Recently, Celio (1990) has noted that CaBP is found in many neurons that generate calcium spikes. Thus, CaBP probably plays several roles in the CNS. Although the function of CaBP in the pretectum is unknown, neurons within the retinal terminal zones (and hence the CaBP cell clusters) do have unique electrophysiological properties that might be related to their CaBP content. Receptive field studies have identified two distinct classes of neuron in the pretectum (Hoffmann and Schoppman, 1981; Ballas and Hoffmann, 1985; Hoffmann and Distler, 1986; Hoffmann, 1989). "Retinal slip" neurons respond to large objects rich in contour that move in a direction-selective manner (Ballas and Hoffmann, 1985; Hoffmann, 1989). These neurons respond to slow velocities and are thought to be driven by retinal W-cell input (Ballas and Hoffmann, 1985; Hoffmann and Stone, 1985). According to Ballas and Hoffmann (1985), "retinal slip" neurons project to the IO and are all located outside the dense clusters of retinal projections to the pretectum.

A second group of neurons named "jerk neurons" respond with a burst of activity to jerklike movements of large visual stimuli. These neurons respond to high stimulus speeds, are non-direction selective, receive a monosynaptic input from $\mathrm{Y}$-cells, and have high transient discharge rates (Ballas and Hoffmann, 1985; Hoffmann, 1989). Although the projection target of these neurons is not known, they are selectively distributed within the retinal terminal zones of the NOT (Ballas and Hoffmann, 1985) and possibly also the PPN (Schoppmann and Hoffmann, 1979). They may therefore be the neurons that contain calbindin. If so, CaBP content is likely related to the discharge patterns of these cells. The high-frequency bursting pattern of jerk neurons would make them susceptible to abrupt increases in calcium concentration as the cell discharges. This rapid calcium influx would require a mechanism for sequestering or buffering the calcium to prevent cell injury.

In fact, recent evidence suggests that neurons in the hippocampus that are resistant to epileptigenic seizures are labeled by CaBP antibodies, while neurons susceptible to seizures (and are probably damaged by calcium) are not labeled by $\mathrm{CaBP}$ (Sloviter, 1989). Calbindin may therefore protect neurons, like jerk neurons, from rapid increases in intracellular calcium. Interestingly, another calcium-binding protein, parvalbumin, has also been localized in ncurons with high-firing frequencies, including those with rapid bursts of activity (for reviews, see Celio, 1986, 1990). In this regard, recent studies in our laboratory show that antibodies to parvalbumin also label large neurons within the pretectal clusters whose morphology appears to be identical to that of CaBP-labeled neurons. The similarities in the distribution of jerk neurons and CaBP- and parvalbumin-labeled neurons in the pretectum suggests a probable function for the calcium-binding proteins in these neurons, and combined function-structure studies should now be able to prove this point.

\section{Reference}

Abols IA, Basbaum AT (1979) The posterior pretectal nucleus: evidence for a direct projection to the inferior olive of the cat. Neurosci Lett 13:111-116.

Adams JC (1981) Heavy metal intensification of DAB-based HRP reaction product. J Histochem Cytochem 29:775.

Avendano C, Juretschke MA (1980) The pretectal region of the cat: a structural and topographical study with sterotaxic coordinates. J Comp Neurol 193:69-88.

Baimbridge K, Miller JJ (1982) Immunohistochemical localization of calcium-binding protein in the cerebellum, hippocampal formation, and olfactory bulb of the rat. Brain Res 245:223-229.

Ballas I, Hoffmann K-P (1985) A correlation between receptive field properties and morphological structures in the pretectum of the cat. J Comp Neurol 238:417-428.

Berman AL, Jones EG (1982) The thalamus and basal telencephalon of the cat. Madison: University of Wisconsin.

Berman N (1977) Connections of the pretectum in the cat. J Comp Neurol 174:227-254.

Bronner F, Pansu D, Stein WD (1986) Analysis of calcium transport in rat intestine. Adv Exp Med Biol 208:227-234.

Capowski JJ (1989) Computer techniques in neuroanatomy. New York: Plenum.

Celio MR (1986) Parvalbumin in most gamma-aminobutyric acidcontaining neurons of the rat cerebral cortex. Science 231:995-997.

Celio MR (1990) Calbindin D-28K and parvalbumin in the rat nervous system. Neuroscience 35:375-475.

Cucchiaro JB, Bickford ME, Sherman SM (1991) A GABAergic projection from the pretectum to the dorsal lateral geniculate nucleus of the cat. Neuroscience 41:213-226.

DeFelipe J, Hendry SHC, Jones EG (1989) Synapses of double bouquet cells in monkey cerebral cortex visualized by calbinin immunoreactivity. Brain Res 503:49-54.

DiFiglia M, Christakos S, Aronin N (1989) Ultrastructural localization of immunoreactive calbindin-D $28 \mathrm{~K}$ in the rat and monkey basal ganglia, including subcellular distribution with colloidal gold labeling. J Comp Neurol 279:653-665.

Fitzpatrick D, Penny GR, Schmechel DE (1984) Glutamic acid decarboxylase immunoreactive neurons and terminals in the lateral geniculate nucleus of the cat. J Neurosci 4:1809-1829.

Garey LJ, Powell TPS (1968) The projection of the retina in the cat. J Anat 102:189-222.

Gerfen CR, Baimbridge KG, Miller JJ (1985) The neostriatal mosaic: compartmental distribution of calcium-binding protein and parvalbumin in the basal ganglia of the rat and monkey. Proc Natl Acad Sci USA 82:8780-8784.

Giolli RA, Peterson GM, Ribak CE, McDonald HM, Blanks RHI, Fallon JH (1985) GABAergic neurons comprise a major cell type in rodent visual relay nuclei: an immunocytochemical study of pretectal and accessory optic nuclei. Exp Brain Res 61:194-203.

Graham J (1977) An autoradiographic study of the efferent connections of the superior colliculus in the cat. J Comp Neurol 173:629654.

Graybiel AM, Berson DM (1980) Autoradiographic evidence for a projection from the pretectal nucleus of the optic tract to the dorsal lateral geniculate complex in cat. Brain Res 195:1-12.

Heizmann CW, Berchtold MW (1987) Expression of parvalbumin and other $\mathrm{Ca}^{2+}$ binding proteins in normal and tumor cells. A topical review. Cell Calcium 8:1-41.

Hendry SH, Jones EG, Emson PC, Lawson DE, Heizmann CW, Streit $P$ (1989) Two classes of cortical GABA neurons defined by differential calcium-binding protein immunoreactivities. Exp Brain Res 76:467-472.

Hoffmann K-P (1989) Functional organization in the optokinetic system of mammals. In: Fundamentals of memory formation: neuronal plasticity and brain function (Rahmann, ed), pp 261-271. Struttgart: Gustav Fisher.

Hoffmann K-P, Distler C (1986) The role of direction selective cells 
in the nucleus of the optic tract of cat and monkey during optokinetic nystagmus. In: Adaptive processes in visual and oculomotor systems (Keller EL, Zee DS, eds), pp 261-266. Oxford: Pergamon.

Hoffmann K-P, Schoppmann A (1981) A quantitative analysis of the direction-specific response of neurons in the cat's nucleus of the optic tract. Exp Brain Res 42:146-157.

Hoffmann K-P, Stone J (1985) Retinal input to the nucleus of the optic tract of the cat assessed by antidromic activation of ganglion cells. Exp Brain Res 59:395-403.

Hoffmann K-P, Ballas I, Wagner H-J (1984) Double labelling of retinofugal projections in the cat: a study using anterograde transport of ${ }^{3} \mathrm{H}$-proline and horseradish peroxidase. Exp Brain Res 53:420-430.

Horn AKE, Hoffmann K-P (1987) Combined GABA-immunocytochemistry and TMB-HRP histochemistry of pretectal nuclei projecting to the inferior olive in rats, cats and monkey. Brain Res 409:133138.

Hutchins R, Weber JT (1985) The pretectal olivary nucleus of the cat: evidence for a two-tailed structure. Brain Res 331:150-154.

Itoh K (1977) Efferent projections of the pretectum in the cat. Exp Brain Res 30:89-106.

Jones EG, Hendry SHC (1989) Differential calcium binding protein immunoreactivity distinguishes classes of relay neurons in monkey thalmic nuclei. Eur J Neurosci 1:222-246.

Kanaseki T, Sprague JM (1974) Anatomical organization of pretectal nuclei and tectal laminae in the cat. J Comp Neurol 158:319-338.

Kawamura S, Sprague JM, Nimi K (1974) Corticofugal projections from the visual cortices to the thalamus, pretectum and superior colliculus in the cat. J Comp Neurol 158:339-362.

Koontz MA, Rodieck RW, Farmer SG (1985) The retinal projection to the cat pretectum. J Comp Neurol 236:42-59.

Kubota T, Morimoto M, Kanaseki T, Inomata H (1987) Projection from the pretectal nuclei to the dorsal lateral geniculate nucleus in the cat: a wheat germ agglutinin-horseradish peroxidase study. Brain Res 421:30-40.

Laties AM, Sprague JM (1966) The projection of optic fibers to the visual centers in the cat. J Comp Neurol 127:35-70.

Mize RR (1989) The analysis of immunohistochemical data. In: Computer techniques in neuroanatomy (Capowski JJ, ed), pp 333-372. New York: Plenum.

Mize RR, Jeon CJ, Butler GD, Emson PC (1991) The calcium binding protein calbindin-D $28 \mathrm{~K}$ reveals subpopulations of projection and interneurons in the cat superior colliculus. J Comp Neurol 307:417436.

Mugnaini E, Oertel WH (1985) An atlas of the distribution of GABAergic neurons and terminals in the rat CNS as revealed by GAD immunohistochemistry. In: Handbook of chemical neuroanatomy, GABA and neuropeptides in the CNS, Vol 4, Pt 1 (Bjorklund A, Hokfelt T, eds), pp 436-595. Amsterdam: Elsevier.

Nabors LB, Mize RR (1990) Antibodies to calbindin delineate retinal projection zones within the pretectum. Soc Neurosci Abstr 16:109.

Nunes Cardozo JJ, Van der Want JJL (1990) Ultrastructural organization of the retino-pretecto-olivary pathway in the rabbit: a combined WGA-HRP tracing and GABA immunocytochemical study. J Comp Neurul 291:313-327.

Oertel WH, Mugnaini E (1984) Immunocytochemical studies of GABAergic neurons in rat basal ganglia and their relations to other neuronal systems. Neurosci Lett 47:233-238.

Ottersen OP, Storm-Mathisen J (1984) GABA-containing neurons in the thalamus and pretectum of the rodent. Anat Embryol 170:197207.

Penny GR, Conley M, Schmechel DE, Diamond IT (1984) The distribution of glutamic acid decarboxylase immunoreactivity in the diencephalon of the opossum and rabbit. J Comp Neurol 228:38-56.

Ribak CE, Vaughn JE, Roberts E (1979) The GABA neurons and their axon terminals in rat corpus striatum as demonstrated by GAD immunocytochemistry. J Comp Neurol 187:261-284.
Robertson RT (1983) Efferents of the prectectal complex: separate populations of neurons project to lateral thalamus and to inferior olive. Brain Res 258:91-95.

Röhrenbeck J, Wässle H, Heizmann CW (1987) Immunohistochemical labelling of horizontal cells in mammalian retina using antibodies against calcium-binding proteins. Neurosci Lett 77:255-260.

Rose JE (1942) The thalamus of the sheep: cellular and fibrous structure and comparison with pig, rabbit, and cat. J Comp Neurol 77: 469-523.

Rye DB, Saper CB, Wainer BH (1984) Stabilization of the tetramethylbenzidine (TMB) reaction product: application for retrograde and anterograde tracing and combination with immunocytochemistry. $\mathrm{J}$ Histochem Cytochem 32:1145-1153.

Scalia F, Arango V (1979) Topographic organization of the projections of the retina to the pretectal region in the rat. J Comp Neurol 186: 271-292.

Schoppmann A, Hoffmann K-P (1979) A comparison of visual responses in two pretectal nuclei and in the superior colliculus of the cat. Exp Brain Res 35:495-510.

Simpson JI, Giolli RA, Blanks RHI (1988) The pretectal nuclear complex and the accessory optic system. In: Neuroanatomy of the oculomotor system (Buttner-Ennever JA, ed), pp 335-364. New York: Elsevier.

Sloviter RS (1989) Calcium-binding protein (Calbindin-D 28K) and parvalbumin immunocytochemistry: localization in the rat hippocampus with specific reference to the selective vulnerability of hippocampal neurons to seizure activity. J Comp Neurol 280:183-196.

Spencer RF, Mize RR, Baker R (1983) Retinal projections to cat pretectum labelled by anterograde transport of peroxidase-conjugated lectin. Invest Ophthalmol Vis Sci [Suppl] 24:227.

Stichel CC, Singer W, Heizmann CW, Norman AW (1986) Ontogeny of calcium-binding proteins, parvalbumin and calbindin-D $28 \mathrm{~K}$, in the dorsal lateral geniculate nucleus (LGNd) of the cat. Neurosci Lett [Suppl] 26:S55.

Stichel CC, Singer W, Heizmann CW, Norman AW (1987) Immunohistochemical localization of calcium-binding proteins, parvalbumin and calbindin-D $28 \mathrm{~K}$, in the adult developing visual cortex of cats: a light and electron microscopic study. J Comp Neurol 263:563577.

Swanson LW, Cowan WM, Jones EG (1974) An autoradiographic study of the efferent connections of the ventral lateral geniculate nucleus of the albino rat and the cat. J Comp Neurol 156:143-163.

Updyke BV (1977) Topographic organization of the projections from cortical areas 17,18 , and 19 onto the thalamus, pretectum and superior colliculus in the cat. J Comp Neurol 173:81-122.

Van Brederode JFM, Mulligan KA, Hendrickson AE (1990) Calciumbinding proteins as markers for subpopulations of GABAergic neurons in monkey striate cortex. J Comp Neurol 298:1-22.

Van der Want JJL, Nunes Cardozo JJ (1988) GABA immuno-electron microscopic study of the nucleus of the optic tract in the rabbit. $J$ Comp Neurol 271:229-242.

Walberg F, Nordby T, Hoffmann K-P, Hollander H (1981) Olivary afferents from the pretectal nuclei in the cat. Anat Embryol 161:291304.

Wasserman RH, Fullmer CS (1982) Vitamin D-induced calcium binding protein. In: Molecular biology (Cheung WYH, ed), pp 175-216. New York: Academic.

Weber JT, Chen I-L (1984) GAD immunoreactivity in the pretectal complex of the cat. Soc Neurosci Abstr 10:576.

Weber JT, Hutchins B (1982) The demonstration of a retinal projection to the medial pretectal nucleus in the domestic cat and the squirrel monkey: an autoradiographic analysis. Brain Res 232:181-186.

Wenthold RJ, Zempel JM, Parakkal MH, Reeks KA, Altshuler RA (1986) Immunocytochemical localization of GABA in the cochlear nucleus of the guinea pig. Brain Res 380:7-18. 